\title{
High conversion efficiency of crystalline Si solar cells using black-Si fabricated by SSCT method
}

\author{
Kentaro Imamura, Yuya Onitsuka, Yuya Sakae, Hikaru Kobayashi *
}

\begin{abstract}
We have developed a technology for fabrication of black - Si by use of the surface structure chemical transfer (SSCT) method. The ultralow reflectance below $3 \%$ results from formation of a graded porosity structure of a nanocrystalline Si layer formed by the SSCT method. The nanocrystalline Si layer with an extremely large surface area is effectively passivated by deposition of phosphosilicate glass (PSG) followed by heat treatment at $925^{\circ} \mathrm{C}$. After PSG passivation, the minority carrier lifetime greatly increases, and the internal quantum efficiency in the short wavelength region is also greatly increased. Using the SSCT method and the PSG passivation method, the high conversion efficiency of $19.7 \%$ is achieved.
\end{abstract}

K e y w o r d s: surface structure chemical transfer, black Si, Si solar cells, surface passivation, reflectance, phosphosilicate glass

\section{Introduction}

Black - Si attracts much interest mainly because of its ultralow reflectance which can apply to crystalline Si solar cells. Black - Si wafers have been produced using reactive ion etching [1-4], metal-assisted chemical etching [5-10], stain etching [11], electrochemical etching [11,12], vapor chemical etching [13], surface structure chemical transfer (SSCT) [14-16], etc. Reactive ion etching [1-4] requires an expensive apparatus, and throughput is considerably low, leading to high fabrication costs. Using stain etching, electrochemical etching, and vapor chemical etching, porous $\mathrm{Si}$ is produced [11-13], resulting in ultralow reflectance, while high conversion efficiencies exceeding $17 \%$ have not been achieved most probably due to poor electrical characteristics of porous Si. Metal-assisted chemical etching [5-10] mainly uses silver $(\mathrm{Ag})$ particles on $\mathrm{Si}$ immersed in hydrofluoric acid (HF) plus hydrogen peroxide $\left(\mathrm{H}_{2} \mathrm{O}_{2}\right)$ solutions, and due to the promoted reaction by $\mathrm{Ag}, \mathrm{Ag}$ moves into $\mathrm{Si}$, forming cylindrical pore structure. The demerits of this method may be: (i) - difficulty of control of pore direction, (ii) - difficulty of complete removal of $\mathrm{Ag}$, and (iii) - difficulty in the fabrication of high quality pnjunction, and (iv) - high surface area, resulting in high surface recombination rates. It is suggested that complete removal of $\mathrm{Ag}$ after formation of nanoporous black- $\mathrm{Si}$ structure is an important factor to increase the conversion efficiency [17]. Formation of uniform pn-junction in black - $\mathrm{Si}$ is also important for improvement of quantum efficiencies in the short wavelength region and the conversion efficiency [18].

Although formation of nanostructures greatly decreases reflectance, their large surface area greatly increases surface recombination rates, leading to a decrease of the quantum efficiency in the short wavelength region and to a reduction in the photovoltage. For surface passivation of black $-\mathrm{Si}$, formation of an $\mathrm{SiO}_{2}$ layer $[5,10]$, deposition an $\mathrm{Al}_{2} \mathrm{O}_{3}$ layer $[2,4,8,19]$, and deposition of silicon nitride (SiN) layer $[1,3,6]$ have been investigated. Another method to decrease the surface recombination rate utilizes wet chemical etching to enlarge pore sizes $[5,9]$. Matsumura et al, [20] removed the cylindrical pore layer formed on multicrystalline $\mathrm{Si}(\mathrm{multi}-\mathrm{Si})$ wafers by alkaline etching. After alkaline etching, pn-junction can be produced but the reflectance becomes considerably high, ie higher than 10\%. Similar technique is applied to multi - Si wafers produced by the fixed abrasive technology, and $18.3 \%$ conversion efficiency is achieved [21].

The conventional method to form low reflectance $\mathrm{Si}$ wafers employs anisotropic etching using strong alkaline solutions such as $\mathrm{KOH}$ and $\mathrm{NaOH}$ with eg isopropanol $[22,23]$. The anisotropic alkaline etching results in the formation of pyramidal structure because the etching rate of $\mathrm{Si}(111)$ surfaces is only thirty-fifth of that for $\mathrm{Si}(100)$ surfaces [24]. However, the anisotropic alkaline etching method cannot be applied to multi-Si wafers with various surface orientations. For multi-Si Si wafers, acid etching using $\mathrm{HF}$ plus nitric acid $\left(\mathrm{HNO}_{3}\right)$ aqueous solutions is used to form textured surfaces $[25,26]$, but the reflectance cannot be decreased to less than $20 \%$.

For slicing Si ingots to produce Si wafers for solar cell use, two different methods, ie the fixed abrasive grain method and the free abrasive grain method, have been developed. The fixed abrasive grain method can produce Si wafers with much higher fabrication rates. Therefore, for production of multi - Si wafers, the free abrasive grain technology is mainly used.

In the present study, a nanocrystalline Si layer is fabricated using the SSCT method, ie contact of Pt catalyst attached to a roller with $\mathrm{Si}$ wafers immersed in $\mathrm{H}_{2} \mathrm{O}_{2}$

* Institute of Scientific and Industrial Research, Osaka University, 8-1 Mihogaoka, Ibaraki, Osaka 567-0047, Japan, k.imamura@sanken. osaka-u.ac.jp 
plus HF solutions. The nanocrystalline Si layer is passivated by deposition of a phosphosilicate glass (PSG) layer followed by heat treatment, which simultaneously forms pn-junction. The SSCT method can produce ultralow reflectance surfaces for both mono-crystalline $\mathrm{Si}$ (mono-Si) and multi-Si wafers produced with the fixed abrasive grain method.

\section{Experiments}

Two kinds of Si substrates, $725 \mu$ m-thick boron-doped p-type CZ $\operatorname{Si}(100)$ wafers with $3 \sim 4 \Omega \mathrm{cm}$ resistivity and $190 \mu$ m-thick multi - Si Si wafers produced by the fixed abrasive grain technology, were used for starting materials. The Si wafers were cleaned using the RCA method. The rear Si surface was coated with a photoresist film, and then the $\mathrm{Si}$ wafers were immersed in a hydrogen peroxide $\left(\mathrm{H}_{2} \mathrm{O}_{2}\right)$ plus hydrofluoric acid ( $\left.\mathrm{HF}\right)$ aqueous solution at room temperature. A platinum $(\mathrm{Pt})$ catalyst installed on a roller was contacted with the Si wafer and moved on it at $4 \mathrm{~cm} / \mathrm{s}$ for $15 \mathrm{~s}$. The pn-junction on the front Si surface and back-surface-field (BSF) on the rear Si surface were produced by deposition of phosphorus and boron compounds, respectively, followed by heat treatment at $925{ }^{\circ} \mathrm{C}$ in nitrogen for $30 \mathrm{~min}$. A front Ag electrode was fabricated by use of $\mathrm{Ag}$ paste and a back $\mathrm{Ag}$ electrode was formed by the vacuum evaporation method. In some cases, a hydrogen treatment was carried under two different conditions: (i) - in $5 \mathrm{vol} \% \mathrm{H}_{2}$ at $400{ }^{\circ} \mathrm{C}$ in for $10 \mathrm{~min}$, and (ii) - in pure $\mathrm{H}_{2}$ at $450{ }^{\circ} \mathrm{C}$ in for $30 \mathrm{~min}$.

Reflectance spectra were measured by use of a JASCO V-670 UV-visible spectrometer with an integrating sphere. Ellipsometry spectra were recorded using a Sopra GES5 ellipsometer. Scanning electron micrography (SEM) measurements were performed using a Hitachi HighTechnologies S-5500 microscope. Transmission electron micrography (TEM) measurements were carried out with a JEOL JEM-3000F microscope with $300 \mathrm{keV}$ incident electron energy. Effective carrier lifetime was measured at an injection level of $10^{15} \mathrm{~cm}^{-3}$ by use of a Sinton Instruments WCT-120 apparatus. Current-voltage (I-V) measurements were performed under AM $1.5100 \mathrm{~mW} / \mathrm{cm}^{2}$ irradiation with a YAMASHITA DENSO YSS-50A solar simulator. Quantum efficiency was measured using a Bunkoukeiki BQE-100 spectrometer.

\section{Results}

Figure 1 shows the reflectance of $\mathrm{Si}$ wafers. The flat Si wafers possessed considerably high reflectance because of the difference in the refractive indexes between air (ie unity) and $\mathrm{Si}(5.57$ at $400 \mathrm{~nm}, 3.94$ at $600 \mathrm{~nm}$, and 3.68 at $800 \mathrm{~nm}$ ). After anisotropic $\mathrm{KOH}$ etching to form pyramidal textured Si surfaces on mono - Si wafers (curve a), the reflectance decreased to, eg $21 \%$ at $400 \mathrm{~nm}$ and $9 \%$ at $800 \mathrm{~nm}$. For multi - Si wafers (curve b), the conventional acid etching method decreased the reflectance to eg $32 \%$ at $400 \mathrm{~nm}$ and $20 \%$ at $800 \mathrm{~nm}$, which was approximately $10 \%$ higher than that for the pyramidal textured surfaces of mono-Si wafers.

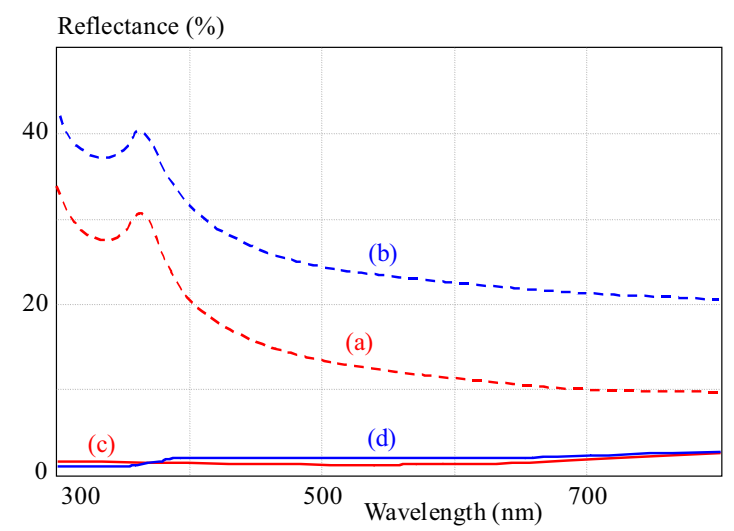

Fig. 1. Reflectance spectra of Si wafers observed after the following treatments : (a) - alkaline etching of mono-Si wafers, (b) acid etching of multi - Si wafers, (c) SSCT treatment of mono-Si wafers, (d) SSCT treatment of multi-Si wafers produced by the fixed abrasive grain technology

When the SSCT treatment was performed on mono - Si (curve c) and multi-Si (curve d) wafers, the reflectance of both kinds of wafers became less than $3 \%$ in the wide wavelength region between 300 and $800 \mathrm{~nm}$. It should be noted that alkaline etching to form the pyramidal structure requires $20 \sim 30 \mathrm{~min}$, while the SSCT treatment
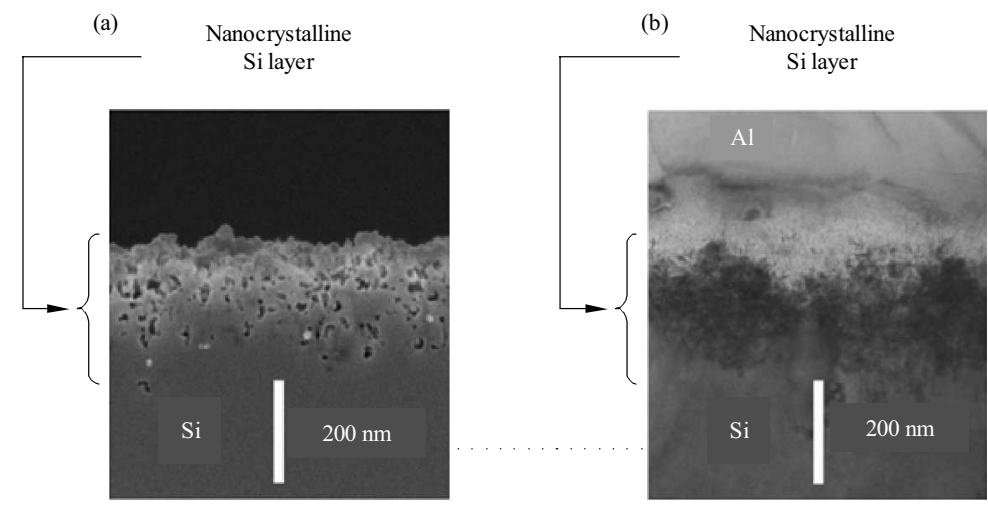

(c)

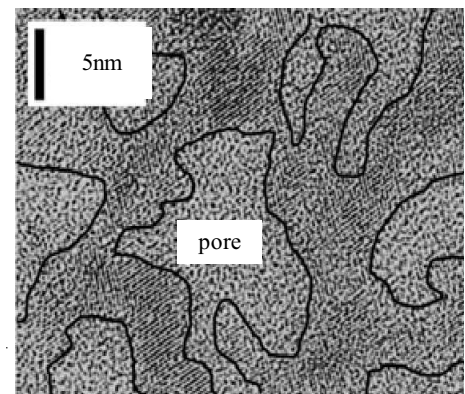

Fig. 2. Cross-sectional SEM micrograph (a) - and TEM micrograph (b) of the nanocrystalline Si layer/mono-Si structure formed by the SSCT treatment, and high resolution cross-sectional TEM micrograph (c) in the surface region of the nanocrystalline Si layer 


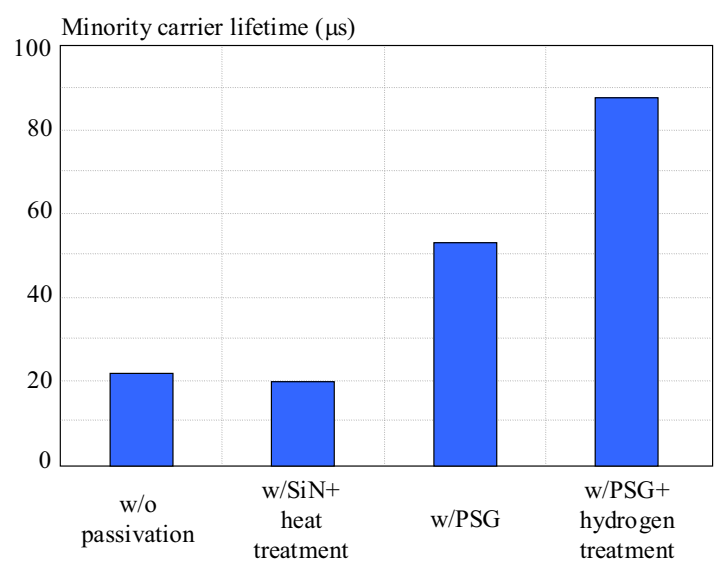

Fig. 3. Minority carrier lifetime of the < nanocrystalline $\mathrm{Si} / \mathrm{mono}-$ $\mathrm{Si} /$ nanocrystalline $\mathrm{Si}>$ symmetric structures with and without surface passivation

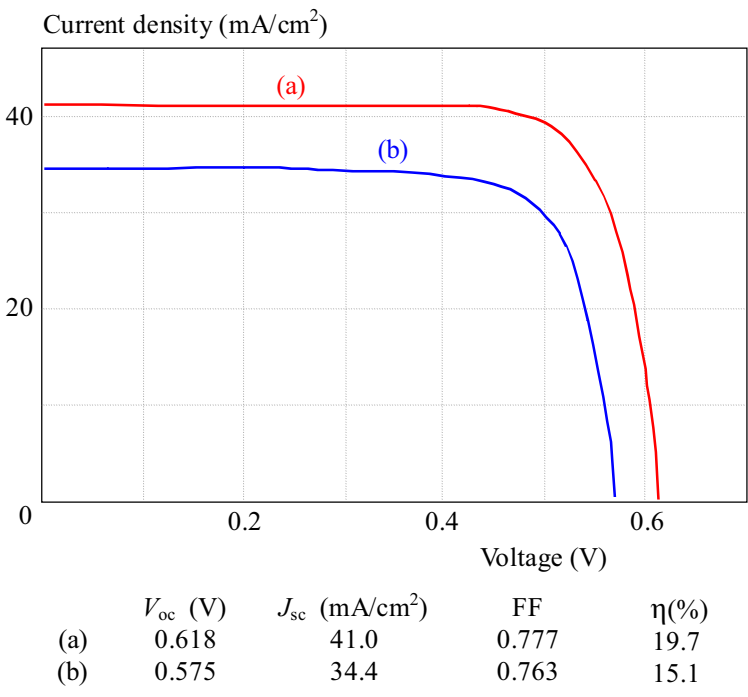

Fig. 4. $\mathrm{I}-\mathrm{V}$ curves of the $<$ nanocrystalline $\mathrm{Si} / \mathrm{n}^{+}-\mathrm{Si} / \mathrm{p}-\mathrm{Si}$ substrate $/ \mathrm{p}^{+}-\mathrm{Si}>$ solar cells: $(\mathrm{a})$ - with PSG plus hydrogen passivation, (b) - without surface passivation

period is only $15 \mathrm{~s}$. It is also noted that conventional acid etching cannot form low reflectance textured surfaces from multi-Si wafers produced by the fixed abrasive grain technology.

Figure 2 shows the cross-sectional SEM (micrographs a) and cross-sectional TEM (micrographs b and c) micrographs for the surface regions of mono - Si wafers after the SSCT treatment. Many pores formed by dissolution of $\mathrm{Si}$ during the SSCT method were observed in the nanocrystalline Si layer (micrograph a). The light color region of micrograph $\mathrm{b}$ is due to low density for the nanocrystalline Si layer. The color becomes darker with the distance from the surface, indicating that the density of the nanocrystalline Si layer increases with the depth.

From the high resolution TEM micrograph c, it is clearly seen that the nanocrystalline Si layer possesses a network structure. All the Si nanocrystals have the same orientation, ie (100) orientation is perpendicular to the $\mathrm{Si}$ substrate surface-parallel direction for all Si nanocrystals. The single orientation means that no grain boundaries are present in the network structure of the nanocrystalline Si layer. Photo-generated electron-hole pairs have a high probability to recombine at defect states such as Si dangling bond states present in grain boundary regions [27]. The absence of grain boundaries avoids grain boundary recombination, leading to the high performance of the solar cells, as described later.

The nanocrystalline Si layer possesses extremely large surface area, leading to a high surface recombination rate. To achieve a high conversion efficiency from the nanocrystalline $\mathrm{Si} /$ crystalline $\mathrm{Si}$ solar cells, surface passivation for the nanocrystalline Si layer is indispensable. Figure 3 shows the minority carrier lifetime for the $<$ nanocrystalline $\mathrm{Si} /$ mono - Si/nanocrystalline Si layer $>$ symmetric structure. Without surface passivation, the minority carrier lifetime was only $21.7 \mu \mathrm{s}$. With conventional surface passivation using deposition of an SiN layer plus heat treatment, the minority carrier lifetime was nearly unchanged. By deposition of a PSG layer plus heat treatment at $925^{\circ} \mathrm{C}$, on the other hand, the minority carrier lifetime was greatly increased to $53.2 \mu \mathrm{s}$, and the subsequent hydrogen treatment at $450{ }^{\circ} \mathrm{C}$ further improved it to $87.6 \mu \mathrm{s}$.

Figure 4 shows the I-V curves measured under AM $1.5100 \mathrm{~mW} / \mathrm{cm}^{2}$ irradiation for the < nanocrystalline $\mathrm{Si} / \mathrm{n}^{+}-\mathrm{Si} / \mathrm{p}-\mathrm{Si}$ substrate $/ \mathrm{p}^{+}-\mathrm{Si}>$ solar cells. The photocurrent density of $41.0 \mathrm{~mA} / \mathrm{cm}^{2}$ was considerably high, leading to the high conversion efficiency of $19.7 \%$, in spite of simple solar cell structure without anti-reflection coating. It should be noted that the practical conversion efficiency of solar cells without antireflection coating is $0.4 \%$ higher than those with antireflection coating when both the conversion efficiencies measured with normalincident light are identical [4].

Figure 5 shows the internal quantum efficiency (IQE) of the $<$ nanocrystalline $\mathrm{Si} / \mathrm{n}^{+}-\mathrm{Si} / \mathrm{p}-\mathrm{Si}$ substrate $/ \mathrm{p}^{+}$ $-\mathrm{Si}>$ solar cells. Without surface passivation, IQE in the wavelength region shorter than $400 \mathrm{~nm}$ was nearly zero. With PSG plus hydrogen passivation, IQE in the short wavelength region greatly increased, eg $81 \%$ at $400 \mathrm{~nm}$ and $55 \%$ at $300 \mathrm{~nm}$.

\section{Discussion}

The SSCT method forms a nanocrystalline Si layer, leading to ultralow reflectivity. To explain the ultralow reflectance, the optical model in which the nanocrystalline Si layer is divided into 19 layer is employed. The refractive index of each nanocrystalline Si layer can be estimated using the Bruggeman effective medium approximation (BEMA) [28]:

$$
\left(1-f_{i}\right) \frac{\varepsilon_{m}-\varepsilon_{i}}{\varepsilon_{m}+2 \varepsilon_{i}}+f_{i} \frac{\varepsilon_{a i r}-\varepsilon_{i}}{\varepsilon_{a i r}+2 \varepsilon_{i}}=0,
$$

where $f_{i}$ is the void fraction of the $\mathrm{i}$-th layer, and $\varepsilon_{i}, \varepsilon_{\text {air }}$, and $\varepsilon_{m}$ are the dielectric functions of the $i$-th nanocrystalline Si layer with void, air (ie 1) and the nanocrystalline Si layer without void, respectively. For estimation 


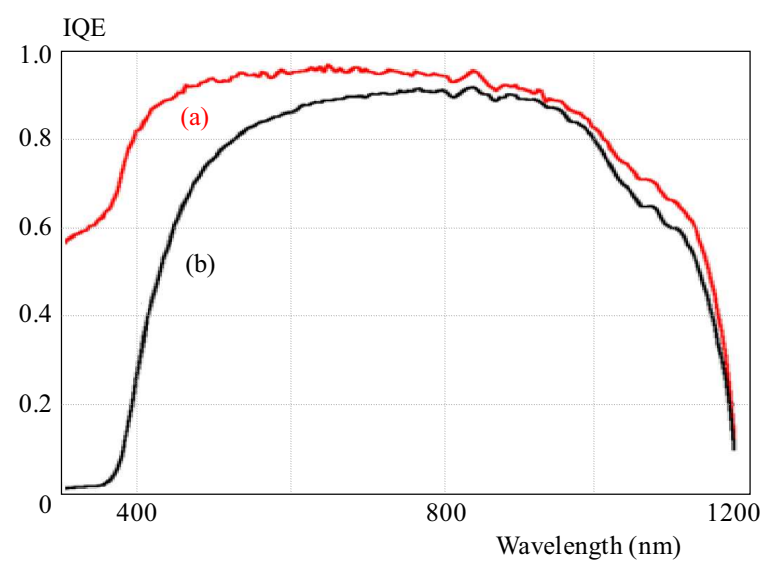

Fig. 5. Internal quantum efficiency of the $<$ nanocrystalline $\mathrm{Si} / \mathrm{n}^{+}$ $-\mathrm{Si} / \mathrm{p}-\mathrm{Si}$ substrate $/ \mathrm{p}^{+}-\mathrm{Si}>$ solar cells: (a) - with PSG plus hydrogen passivation, (b) - without surface passivation

Refractive index (n)

Extinction coefficient $(\mathrm{k})$

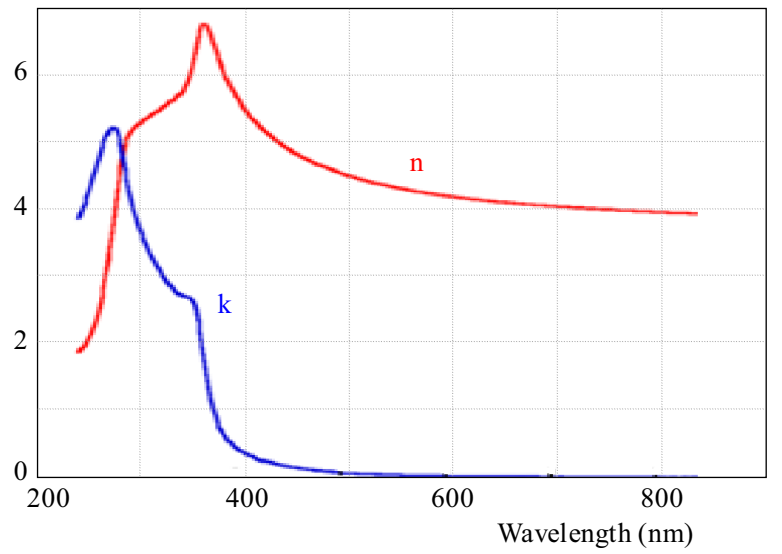

Fig. 6. Refractive index $(n)$ and extinction coefficient $(k)$ of the nanocrystalline $\mathrm{Si}$ layer in the absence of pores $v s$ the wavelength, obtained from ellipsometry measurements

of the dielectric function of the nanocrystalline Si layer, $\varepsilon_{m}$, the nanocrystalline Si layer is assumed to consist of $4.9 \mathrm{~nm}$ Si nanocrystals and Si bulk. The dielectric constant of $4.9 \mathrm{~nm}$ Si nanocrystals is calculated from TaucLorentz model [29] and Kramers-Krönig relation using Tauc-Lorentz parameters of $4.9 \mathrm{~nm}$ Si nanocrystal [30]. (The presence of $4.9 \mathrm{~nm}$ nanocrystalline $\mathrm{Si}$ is evident from the measurement of photoluminescence spectra of the $<$ nanocrystalline $\mathrm{Si}$ layer/mono $-\mathrm{Si}>$ structure with a peak at $705 \mathrm{~nm}[16])$. Figure 6 shows $\varepsilon_{m}$ of the nanocrystalline Si layer vs. the depth estimated from analysis of the ellipsometry data for the nanocrystalline $\mathrm{Si} / \mathrm{mono}-\mathrm{Si}$ structure. The refractive index is obtained with the following procedure: (i) - the relationship of the porosity with the depth is calculated using the ellipsometry data, and (ii) - the relationship of the refractive index with the depth is calculated from the porosity using the BEMA approximation. The porosity is found to decrease almost linearly with the depth, and the average porosity is $48 \%$ which is in good agreement with that estimated from the Si weight loss (ie 51\%), making verification of the analysis method of the ellipsometry data. It is clearly seen that the refractive index monotonically increases with the depth, as shown in Fig. 7. The step-like refractive index resulted from assumed step-like porosity of the nanocrystalline $\mathrm{Si}$ layer divided into 19 layers.

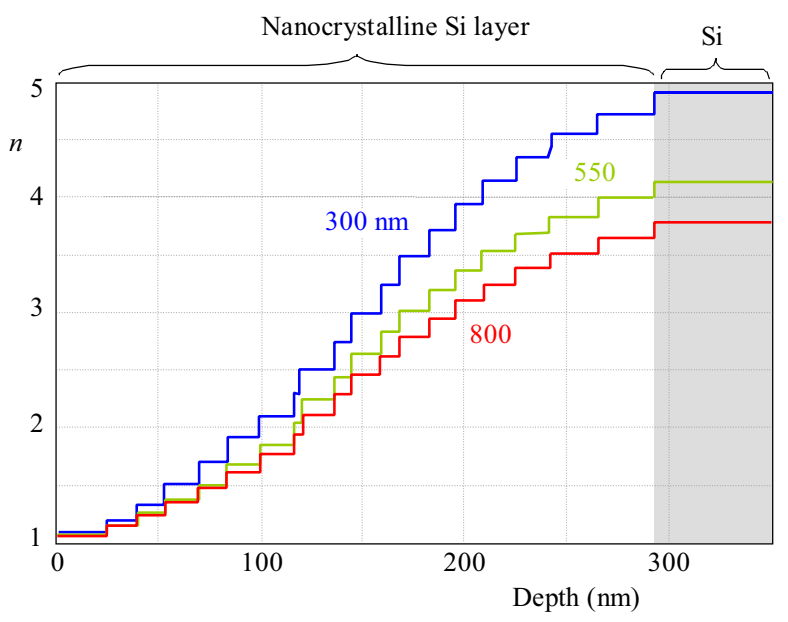

Fig. 7. Refractive index of the nanocrystalline Si layer $v s$ the depth

Figure 8 schematically explains the mechanism of the ultralow reflectance of < nanocrystalline Si layer/crystalline $\mathrm{Si}>$ structure. Due to the average density continuously decreasing with the depth, the refractive index continuously increases with the depth. The reflectance, $R$, is determined by the refractive indexes, $n_{1}$ and $n_{2}$, of the two adjacent phases and that for the normal-incidence is simply given by

$$
R(\%)=\left[\frac{n_{1}-n_{2}}{n_{1}+n_{2}}\right]^{2} \times 100 \%
$$

$i e$ the reflectance is determined by the difference of the refractive indexes. The refractive index of the topmost surface of the nanocrystalline Si layer is estimated to be 1.075 at a $400 \mathrm{~nm}$ wavelength, which is close to that of air, and therefore, the reflectance at the surface is estimated to be only $0.13 \%$. The reflectance in the nanocrystalline Si layer is estimated to be $0.29 \%$ at a $400 \mathrm{~nm}$ wavelength using the multiple reflection model [31]. Therefore, the reflectance at $400 \mathrm{~nm}$ is estimated to be $0.29 \%$, in good agreement with the experimental value of $0.30 \%$. The ultralow reflectance is attributable to the refractive index of the nanocrystalline Si layer continuously increasing with the depth.

Figure 9 shows the models for the surface passivation method. In the case of the method of SiN deposition plus heat treatment, Fig. 9(a), SiN does not penetrate into pores in the nanocrystalline Si layer. In the case of the PSG passivation method, Fig. 9(b), on the other hand, PSG melts by the heat treatment at $925{ }^{\circ} \mathrm{C}$, and fills pores, leading to formation of chemical bonds with nanocrystalline $\mathrm{Si}$, and thus eliminating surface defect states such as Si dangling bonds. Since $\mathrm{SiO}_{2}$ is the main composition of PSG, it is likely that the characteristics 


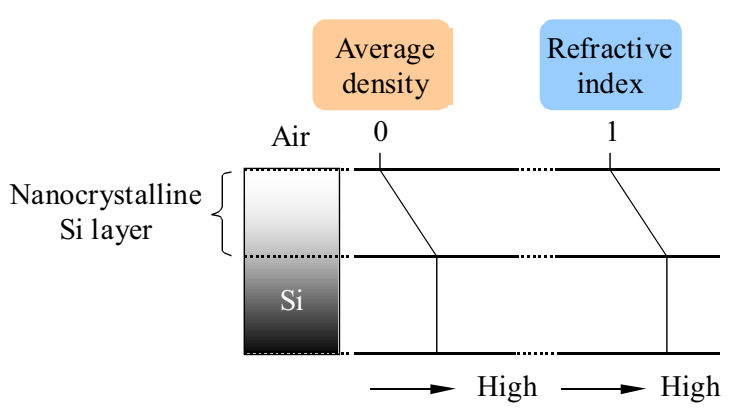

Fig. 8. Models to explain the ultra-low reflectance of the $<$ nanocrystalline $\mathrm{Si} /$ crystalline $\mathrm{Si}>$ structure
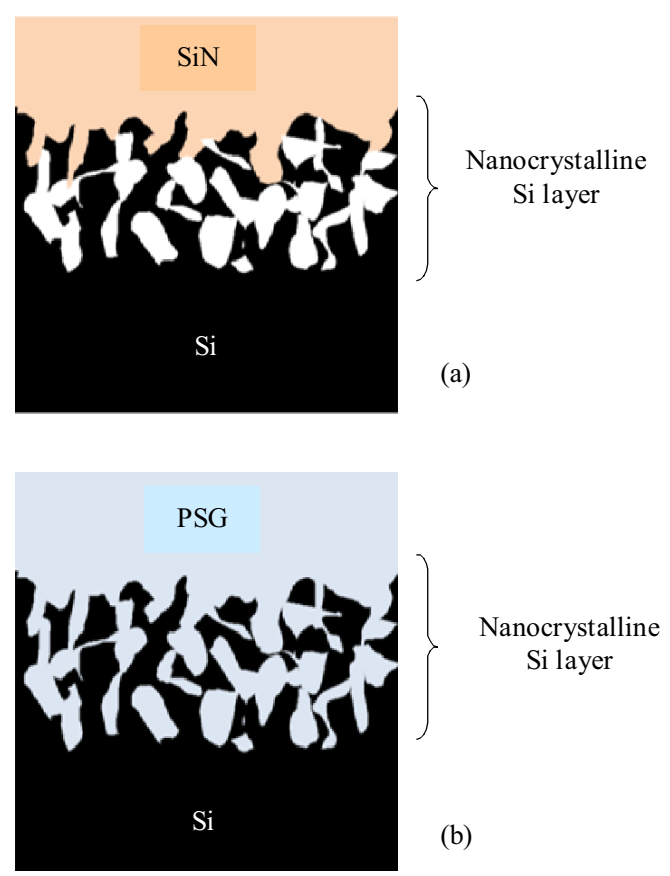

Fig. 9. Models for the surface passivation method: (a) - SiN passivation, (b) - PSG passivation

of the nanocrystalline Si/PSG interface are similar to those of $\mathrm{Si} / \mathrm{SiO}_{2}$ interface with an ultralow interface state density [31].

Analysis of ellipsometry data clarifies that incident light with wavelength shorter than $400 \mathrm{~nm}$ is almost completely absorbed by the nanocrystalline Si layer [16]. Therefore, to obtain a high conversion efficiency from the $<$ nanocrystalline Si layer/crystalline $\mathrm{Si}>$ solar cells, electron-hole pairs generated in the nanocrystalline $\mathrm{Si}$ layer should contribute to a photocurrent. This requirement is satisfied with the solar cells fabricated in the present study for the following reasons: (i) - no grain boundaries are present in the nanocrystalline Si layer, and thus, no grain boundary recombination proceeds, (ii) - surface defect states are effectively passivated by PSG plus hydrogen passivation, (iii) - the nanocrystalline $\mathrm{Si}$ layer possesses a graded band-gap structure which enhances separation of photo-generated electron-hole pairs.
Because of the ultralow reflectance and the effective surface passivation of the nanocrystalline Si layer by use of PSG, the high conversion efficiency of $19.7 \%$ has been achieved in spite of the simple solar cell structure without anti-reflection coating.

\section{Conclusion}

Ultralow reflectance of crystalline $\mathrm{Si}$ is achieved by formation of a nanocrystalline Si layer on the Si substrate by use of the SSCT method. The nanocrystalline Si layer possesses porosity decreasing with the depth, and thus, the refractive index of the nanocrystalline Si layer increases with the depth. Due to the absence of a surface and an interface where the refractive indexes of adjacent phases are largely different, the ultralow reflectance less than $3 \%$ is achieved. A PSG layer formed for formation of pn-junction has an effective surface passivation effect for the nanocrystalline Si layer. With PSG passivation, IQE in the short wavelength region below $400 \mathrm{~nm}$ is greatly improved, and a short circuit photocurrent density of 41.0 $\mathrm{mA} / \mathrm{cm}^{2}$ is achieved, leading to the high conversion efficiency of $19.7 \%$.

\section{Acknowledgements}

This work was supported by CREST, Japan Science and Technology Agency and JSPS KAKENHI Grant Number $15 \mathrm{H} 01997$.

\section{REFERENCES}

[1] J. M. Shim, H. W. Lee, K. Y. Cho, J. K. Seo, J. S. Kim, E. J. Lee, J. Y. Choi, D. J. Oh, J. E. Shin, J. S. Kim, J. H. Kong, S. H. Lee and H. S. Lee, "17. 6\% Conversion Efficiency Multicrystalline Silicon Solar Cells Using the Reactive Ion Etching with the Damage Removal Etching", Int. J. Photoenergy, 2012 (2012) 24818216.

[2] P. Repo, J. Benick, V. Vhnissi, J. Sehn, G. V. Gastrow, B. Steinhauser, M. C. Schubert, M. Hermle and H. Savin, "N Type Black Silicon Solar Cells", Energy Procedia, 38 (2013) 866871.

[3] R. S. Davidsen, H. Li, A. To, X. Wang, A. Han, J. An, J. Colwell, C. Chan, A. Wenham, M. S. Schmidt, A. Boisen, O. Hansen, S. Wenham and A. Barnett, "Black Silicon Laser Doped Selective Emitter Solar Cell with 18. 1\% Efficiency", , Sol.Energy Mater.Sol.Cells 144 (2016) 740747.

[4] H. Savin, P. Repo, G. V. Gastrow, P. Ortega, E. Calle, M. Garin and R. Alcubilla, "Black Silicon Solar Cells with interdigitated Back Contacts Achieve 22. 1\% Efficiency", Nature Nanotech. 10 (2015) 624628.

[5] J. Oh, H. C. Yuan and H. M. Branz, "An 18. $2 \%$ Efficient Black Silicon Solar Cell Achieved Through Control of Carrier Recombination Nanostructures", Nature Nanotech. 7 (2012) 743748.

[6] D. Z. Dimitre and C. H. Du, "Crystalline Silicon Solar Cells with Micro/Nano Texture", Appl.Surf.Sci. 266 (2013) 14.

[7] L. Yang, Y. Liu, Y. Wang, X. Li, W. Chen, Y. Hua, Q. Zhang, J. Fu, H. Liang, Z. Mei and X. Du, "Optimization of Silicon Pyramidal Emitter by Self Selective Ag Assisted Chemical Etching", Rsc Adv. 4 (2014) 2445824462.

[8] W. C. Wang, C. W. Lin, H. J. Chen, C. W. Chang, J. J. Huang, M. J. Yang, B. Tjahjono, J. J. Huang, W. C. Hsu and M. 
J. Chen, "Surface Passivation of Efficient Nanotextured Black Silicon Solar Cells Using thermal Atomic Layer Deposition", Acs Appl. Mater. interfaces, 5 (2013) 97529759.

[9] Z. Zhao, P. Li, Y. Wei, C. Lu, X. Tan and A. Liu, "17. 3\% Efficient Black Silicon Solar Cell without Dielectric Antireflection Coating", Sol.Energy 110 (2014) 714719.

[10] F. Toor, H. M. Branz, M. R. Page, K. M. Jones and H. C. Yuan, "Multi-scale Surface Texture To Improve Blue Response of Nanoporous Black Silicon Solar Cells Appl.Phys.Lett. 99 (2011) 10350113.

[11] R. R. Bilyalov, R. Ldemann, W. Wettling, L. Stalmans, J. Poortmans, J. Nijs, L. Schirone, G. Sotgiu, S. Strehlke and C. Levyclement, "Multicrystalline Silicon Solar Cells with Porous Silicon Emitter", Sol. Ener. Mater. Sol. Cells, 60 (2000) 391420.

[12] L. Stalmans, J. Poortmans, H. Bender, M. Caymax, K. Said, E. Vazsonyi, J. Nijs and R. Mertens, "Porous Silicon Crystalline Silicon Solar Cells: A Review and the Effect on the Internal Quantum Efficiency", Prog.Photovolt. Res. Appl. 6 (1998) 233246.

[13] M. B. Rabha and B. Bessais, "Enhancement of Photovoltaic Properties of Multicrystalline Silicon Solar Cells by Combination of Buried Metallic Contacts and Thin Porous Silicon", Sol.Energy 84 (2010) 486491.

[14] K. Imamura, T. Nonaka, D. Irishika and H. Kobayashi, "Ultralow Reflectivity and Light Trapping For Crystalline Si Solar Cells by Use of Surface Structure Chemical Transfer Method on Pyramidal Textured Surfaces", Ecs Solid State Lett. 4 (2015) Q63Q65.

[15] D. Irishika, K. Imamura and H. Kobayashi, "Ultralow Reflectivity Surfaces by Formation of Nanocrystalline Si Layer For Crystalline Si Solar Cells", Sol. Energ. Mat. Sol. Cells 141 (2015) 16.

[16] K. Imamura, D. Irishika and H. Kobayashi, "Surface Nanocrystalline Si Structure and Its Surface Passivation For Highly Efficient Black Si Solar Cells", Prog. Photovol. in Press.

[17] J. Shi, F. Xu, Z. Ma, P. Zhou, L. Zheng, J. Yang, D. Chen and Z. Jiang, "Nanoporous Black MultiCrystalline Silicon Solar Cells: Realization of Low Reflectance and Explanation of High Recombination Loss", Mater. Sci. Semicond. Process.16 (2013) 441448.

[18] Z. Shen, B. Liu, Y. Xia, J. Liu, S. Zhong and C. Li, "Black Silicon on Emitter Diminishes the Lateral Electric Field and Enhances the Blue Response of A Solar Cell by Optimizing Depletion Region Uniformity", Scr. Mater. 68 (2013) 199202.

[19] E. Calle, P. Ortega, G. V. Gastrow, I. Martin, H. Savin and R. Alcubilla, "LongTerm Stability of $\mathrm{Al}_{2} \mathrm{O}_{3}$ Passivated Black Si", Ener.Procedia 92 (2016) 341346.

[20] K. Tsujino, M. Matsumura and Y. Nishimoto, "Texturization of Multicrystalline Silicon Wafers For Solar Cells by Chemical Treatment Using Metallic Catalyst", Sol. Ener. Mater. Sol. Cells 90 (2006) 100110.

[21] F. Cao, K. Chen, J. Zhang, X. Ye, J. Li, S. Zou and X. Su, "NextGeneration MultlCrystalline Silicon Solar Cells: DiamondWire Sawing", NanoTexture and High Efficiency, Sol. Ener. Mater. Sol. Cells 141 (2015) 132138.

[22] E. Vazsonyi, K. D. Clercq, R. Einhaus, E. Said, K. VanKerschaver, J. Poortmans, J. Szlufcik and J. Nijs, "Improved Anisotropic Etching Process For industrial Texturing of Silicon Solar Cells", Sol. Ener. Mater. Sol. Cells 57 (1999) 179188.

[23] I. Zubel, F. Granek, K. Rola and K. Banaszczyk, "Texturization of Si(100) Substrates Using Tensioactive Compounds", Appl. Surf. Sci. 258 (2012) 90679072.

[24] P. K. Singh, R. Kumar, M. Lal, S. N. Singh and B. K. Das, "?Effectiveness of Anisotropic Etching of Silicon Aqueous Alkaline Solutions", Sol. Energ. Mat. Sol. Cells 70 (2001) 103113.

[25] G. Kulesza, P. Panek and P. Zieęba, "Time Efficient Texturization of Multicrystalline Silicon the $\mathrm{Hf} / \mathrm{HnO}_{3}$ Solutions and Its
Effect on Optoelectronic Parameters of Solar Cells", Arch. Civ. Mech. Eng., 14 (2014) 595601.

$26]$ U. Gangopadhyay, S. K. Dhungel, P. K. Basu, S. K. Dutta, H. Saha and J. Yi, "Comparative Study of Different Approaches of Multicrystalline Silicon Texturing For Solar Cell Fabrication", Sol. Ener. Mater. Sol. Cells 91 (2007) 285289.

27] S. Ribl, O. Breitenstein, "Evaluation of Recombination Velocities of Grain Boundaries Measured by High Resolution Lockin thermography", Ener. Procedia 38 (2013) 161166.

28] D. A. G. Bruggeman, "Berechnung Verschiedener Physikalischer Konstanten Von Heterogenen Substanzen. I. Dielektrizittskonstanten Und Leitfhigkeiten Der Mischkrper Aus Isotropen Substanzen", Ann. Phys. (Leipzig) 416 (1935) 636664.

[29] Jr, G. E. Jellison and F. A. Modine, "Parameterization of the Optical Functions of Amorphous Materials the interband Region", Appl. Phys. Lett. 69 (1996) 371373.

30] A. En Naciri, P. Miska, A. S. Keita, Y. Battie, H. Rinnert and M. Vergnat, "Optical Properties of Uniformly Sized Silicon Nanocrystals within a Single Silicon Oxide Layer", J. Nanopart. Res. 15 (2013) 153819.

31] K. Imamura, D. Irishika and H. Kobayashi, "Mechanism of UltraLow Reflectance For Nanocrystalline Si/Crystalline Si Structure Formed by Surface Structure Chemical Transfer Method", J.Appl.Phys. 121 (2017) 01310715.

32] E. H. Nicollian and J. R. Brews, , Mos (Metal Oxide Semiconductor) Physics and Technology, John Wiley \& Sons, New York.

Received 23 April 2017

Hikaru Kobayashi received the BE degree in chemistry from Osaka University, Osaka, Japan, in 1979 and the ME, and $\mathrm{PhD}$ degrees in chemistry from Kyoto University, Kyoto, Japan, in 1981, and 1984, respectively. From 1984 to 1986, he was a Postdoctoral Research Associate in Department of Physics and Astronomy, University of Pennsylvania, PA. From 1986-1987, he was a Researcher in Matsushita Electronics Corporation Kyoto Research Center, Kyoto, Japan where he was engaged in LSI wiring and gate oxide technology. From 1987 to 1990, he was a Research Associate in Department of Chemistry, Faculty of Engineering Science, Osaka University where he was engaged in research on silicon solar cells, surface and interface science of silicon, and low temperature silicon oxidation. From 1990 to 1998, he has been an Associate Professor in Department of Chemistry, Faculty of Engineering Science, Osaka University. He is currently a Professor in the Institute of Scientific and Industrial Research, Osaka University. He has been engaged in research on silicon solar cells, low temperature $\mathrm{Si}$ oxidation, and fabrication of Si nanopowder and its application to hydrogen generation material, anode material in $\mathrm{Li}$ ion batteries, and luminescent material.

Kentaro Imamura (Assist Prof, Sci, PhD) received his MSc and PhD degrees in chemistry from Osaka University, Osaka, Japan, in 2008 and 2012, respectively. From 2008 to 2012, he was a Researcher in Corporate Research \& Development group of Sharp Corporation, Nara, Japan where he engaged in development of LCD devices. Since 2012, he has been an Assistant professor in the Institute of Science and Industrial Research, Osaka University, Osaka, Japan. His research interests are Si solar cells, especially new chemical methods to improve conversion efficiencies such as surface structure chemical transfer (SSCT) method for achievement of ultralow reflectance and nitric acid oxidation of silicon (NAOS) method for surface passivation, and fabrication and application of nano - Si materials. 